Article

\title{
The Anti-Serotonin Effect of Parthenolide Derivatives and Standardised Extract from the Leaves of Stizolophus balsamita
}

\author{
Joanna Nawrot ${ }^{1}\left(\right.$, Marta Napierała ${ }^{2} \oplus$, Kinga Kaczerowska-Pietrzak ${ }^{1}$, Ewa Florek ${ }^{2}$, \\ Justyna Gornowicz-Porowska ${ }^{1}$, Ewa Pelant ${ }^{1}$ and Gerard Nowak ${ }^{1, *(D)}$ \\ 1 Department of Medicinal and Cosmetic Natural Products, Poznan University of Medicinal Sciences, \\ Mazowiecka 33, 60-623 Poznan, Poland; joannac@ump.edu.pl (J.N.); kingak.pietrzak@gmail.com (K.K.-P.); \\ justynagornowicz1@poczta.onet.pl (J.G.-P.); ewalawniczak@ump.edu.pl (E.P.) \\ 2 Laboratory of Environmental Research, Department of Toxicology, Poznan University of Medicinal Sciences, \\ Dojazd 30, 60-631 Poznan; martan@ump.edu.pl (M.N.); eflorek@ump.edu.pl (E.F.) \\ * Correspondence: gnowak@ump.edu.pl; Tel./Fax: +48-61-8470628
}

Received: 21 October 2019; Accepted: 13 November 2019; Published: 15 November 2019

\begin{abstract}
The presence of dominant active compounds in standardised methanol extract from the leaves of Stizolophus balsamita (S. balsamita) was examined using HPLC with a diode-array detector. The extract and three dominant parthenolide derivatives were tested with Serotonin Research ELISA for their ability to inhibit the serotonin release from platelets. The antiserotonin effect of the extract was compared with that of parthenolide, a compound with proven antiserotonin and antimigraine effects. This study aimed to evaluate the ability of natural parthenolide derivatives to inhibit serotonin release from platelets. Izospiciformin, stizolin and stizolicin were analysed along with the standardised alcohol extract of $S$. balsamita leaves, which also contained four other parthenolide derivatives. All the analysed substances were found to inhibit serotonin release from platelets as compared with the control sample, which had $100 \%$ of serotonin released. Izospiciformin had the most significant impact (97.98\% serotonin release inhibition). The effect of the methanol extract of S. balsamita on the serotonin release inhibition was also statistically significant.
\end{abstract}

Keywords: antiserotonin effect; compositae; Stizolophus balsamita; parthenolide derivatives

\section{Introduction}

Sesquiterpene lactones are commonly identified in many compositae genera and often highlighted as reliable chemosystematic markers [1]. The lactones exert numerous biological activities, e.g., anti-inflammatory, gastroprotective, antibacterial and antimigraine activities [2]. Particularly interesting are germacranolides-parthenolide (Figure 1) and its derivatives, with three elements in the skeleton: 4,5-epoxide and a lactone ring coupled with an exomethylene, which enables inhibition of cellular enzymes through the Michael nucleophilic addition [3].

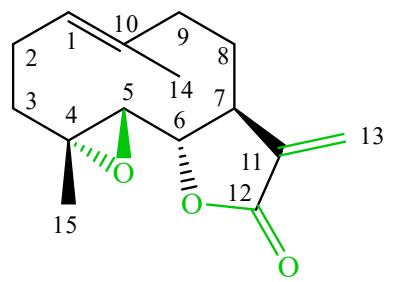

Figure 1. The structure of parthenolide. 
Serotonin (5-HT) is a key molecule in the neurobiology of migraine. It is known that an initial high concentration of serotonin can cause vascular smooth muscle contraction and contribute to migraine aura formation [4]. Low serotonin concentrations, on the other hand, may stimulate perivascular pain fibres by their effect on the release of $\mathrm{NO}$, prostaglandin and other factors responsible for vasodilation activity [5].

Serotonin is stored in enterochromaffin cells located in the lining of the gut $(90 \%)$, platelets and serotonergic neurons of the central nervous system (CNS). Serotonin acts as a neurotransmitter in the CNS and as an autacoid in the nervous circuit-A local hormone with strong vasoconstrictor properties. Serotonin affects the nervous system by activating specific receptors with $5-\mathrm{HT}_{1 \mathrm{~B}}$ (located mostly in the brain vessels) and 5- $\mathrm{HT}_{1 \mathrm{D}}$ (found in the trigeminal nerve endings), playing a crucial part in migraine pathophysiology [6].

Migraine is a severe condition that affects people's health and their socioeconomic situations. It is also a specific pharmacological puzzle, as its multitude of symptoms of unknown aetiology result in patients undergoing only symptomatic treatment.

Natural drugs may be an option for causative migraine treatment. Tanacetum parthenium ( $T$. parthenium), known as feverfew, is a well-studied plant with proven antimigraine properties; the main active compound present in this plant is a parthenolide [7].

The antimigraine effect of parthenolide results from the modification of biochemical pathways, that is, the release of serotonin from platelets is inhibited [8], and the release of neuronal serotonin is reduced without significant effects on the $5-\mathrm{HT}_{2 \mathrm{~A}}$ and $5-\mathrm{HT}_{2 \mathrm{~B}}$ receptors [9].

The extract of T. parthenium herb enriched with parthenolide has been found to significantly reduce nitroglycerin-induced Fos expression in the nucleus trigeminalis caudalis. Purified parthenolide has been shown to significantly inhibit nitroglycerin-induced neuronal activation in additional brain nuclei and activity of nuclear factor-kappa B. These findings strongly suggest that parthenolide might be the component responsible for the biological activity of T. parthenium owing to its antimigraine effect [10]. Unfortunately, the studies showed that the concentration of parthenolide in T. parthenium decreases significantly (13\%) during storage [11].

Another study showed that some phenolic compounds might also be responsible for the antimigraine effect of T. parthenium. These compounds reduce lactate dehydrogenase (LDH) release, nitrite levels and 5-HT, and thus, they cause antioxidant and antiapoptotic effects [12].

The phytochemical profiles of plants in genus Stizolophus show the presence of parthenolide derivatives [1,13], and in their structures, all the elements responsible for the parthenolide activity were observed. For this study, Stizolophus balsamita (S. balsamita) (Lam.) K.Koch from Iran was chosen, as no less than seven parthenolide derivatives were found in it [14].

The presence of parthenolide derivatives in S. balsamita, including balsamin (1), izospiciformin (2), stizolin (3), $9 \alpha$-hydroxyparthenolide (4), $8 \alpha-E$-(4'-hydroxy)-senecioyloxy- $9 \alpha$-hydroxyparthenolide (5), 11ßH,13-dihydrostizolicin (6) and stizolicin (7) [14,15] (Figure 2), induces authors to test for antiserotonin properties of the three germacranolides-2, 3, 7-and the methanol extract isolated from the leaves of $S$. balsamita. Our research shows that through the thin-layer chromatography method a detailed description of the chemical structure of parthenolide derivatives may be obtained (Figure S1). 


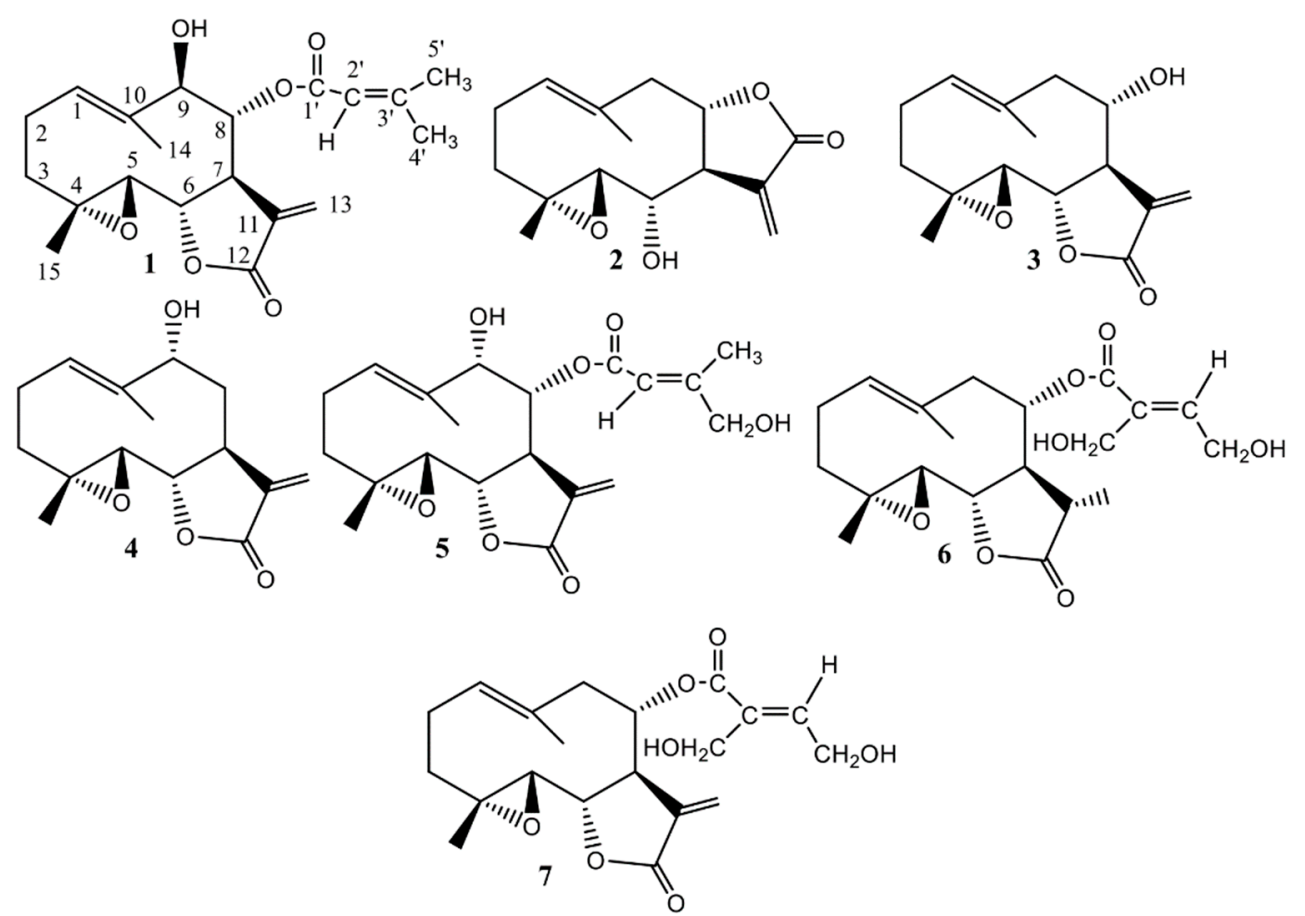

Figure 2. Chemical structures of compounds isolated from the leaves of Stizolophus balsamita (S. balsamita).

\section{Results and Discussion}

The amounts of characteristic compounds 2, 3 and 7 in the methanol extract from the leaves of $S$. balsamita was determined using HPLC (Figure 3).

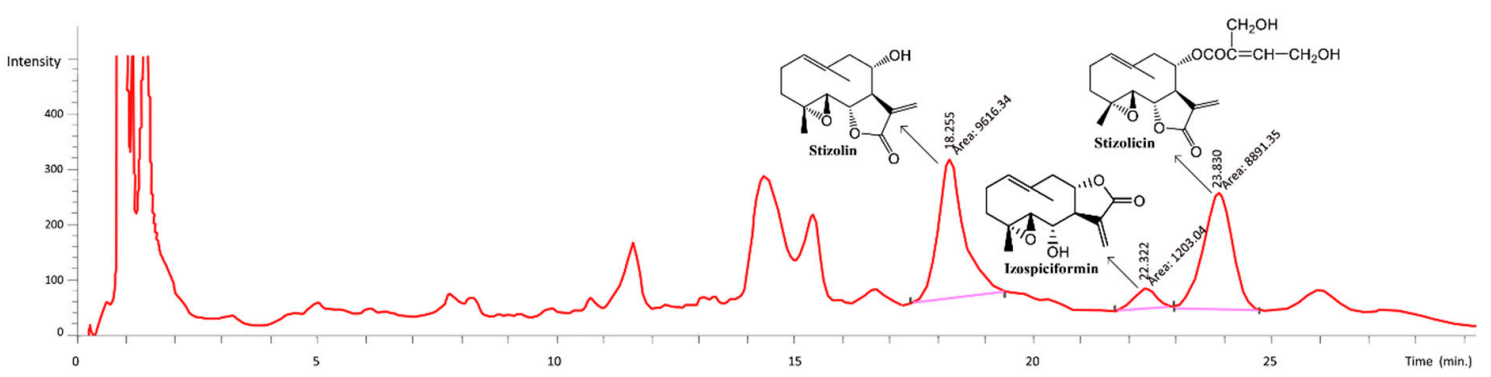

Figure 3. The HPLC chromatogram of the methanol extract from the S. balsamita leaves.

The amounts of the three compounds are as follows: compound $2,0.04 \mathrm{mg} / \mathrm{mL}(2.22 \mathrm{mg} / \mathrm{g}$ of the extract); compound 3, $0.44 \mathrm{mg} / \mathrm{mL}$ ( $22.05 \mathrm{mg} / \mathrm{g}$ of the extract); compound $7,0.33 \mathrm{mg} / \mathrm{mL}(16.5 \mathrm{mg} / \mathrm{g}$ of the extract). The concentrations of these compounds were all $40.77 \mathrm{mg} / \mathrm{g}(4.08 \%)$. More importantly, the concentrations of the active compounds in S. balsamita leaves did not change over a considerable time (no measurable decrease for at least three years), and their pharmacological activities were constant (Figure S2).

The concentration of serotonin $(\mathrm{ng} / \mathrm{mL})$ in the samples containing parthenolide, compounds 2,3 and $\mathbf{6}$ and in the methanol extract of the S. balsamita leaves were significantly lower than that in the control sample (Table 1 and Figure 4, Figures S3-S6). 
Table 1. The concentration of serotonin in the samples with the analysed substances and in the control samples.

\begin{tabular}{cccc}
\hline $\mathbf{N}$ & Sample & Average Serotonin Concentration $\mathbf{( n g} / \mathbf{m L})$ & Standard Deviation \\
\hline 12 & Control & 11.44 & 7.42 \\
12 & Parthenolide & 5.90 & 2.11 \\
9 & Izospiciformin & 0.23 & 0.19 \\
12 & Stizolin & 4.72 & 1.36 \\
12 & Stizolicin & 6.62 & 1.08 \\
12 & Methanol extract from & 3.48 & 2.21 \\
\hline
\end{tabular}

$\mathrm{N}=$ number of valid results.

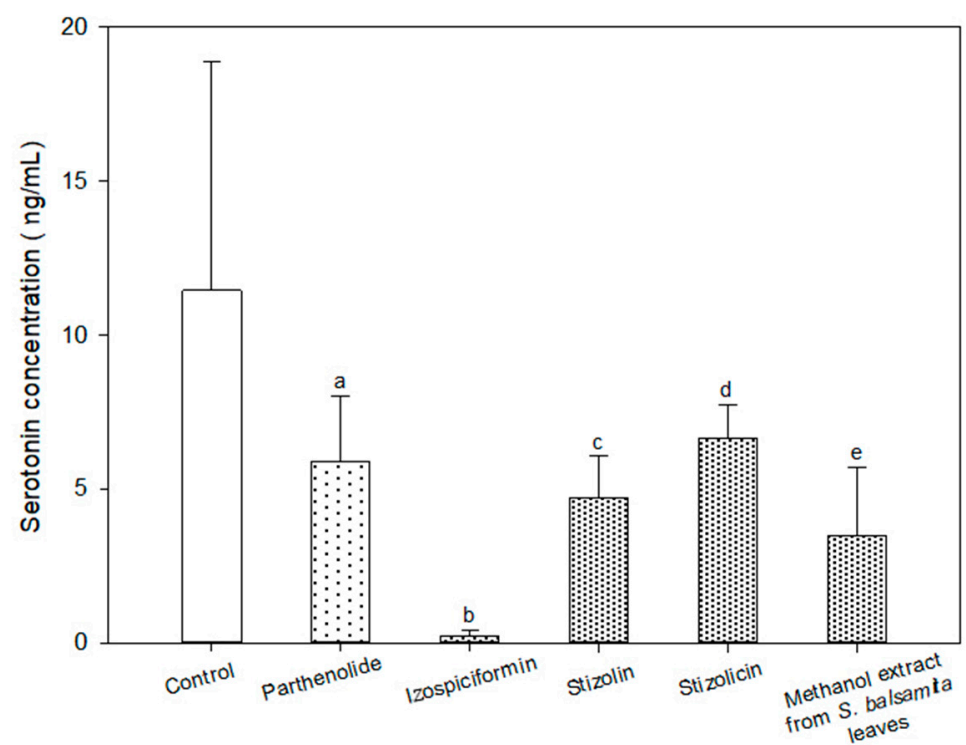

Figure 4. Serotonin concentration (average $\pm \mathrm{SD} ; \mathrm{ng} / \mathrm{mL}$ ) in the sample after the administration of analysed substances: parthenolide (a), izospiciformin (b), stizolin (c), stizolicin (d) and methanol extract from the $S$. balsamita leaves (e). a-statistically significant difference compared to the control sample $(p=$ 0.0477); b-statistically significant difference compared to the control sample $(p=0.0001)$; c-statistically significant difference compared to the control sample $(p=0.0380)$; $\mathrm{d}$-statistically significant difference compared to the control sample $(p=0.0389)$; $\mathrm{e}$ - statistically significant difference compared to the control sample $(p=0.0097)$.

One can assume that the mechanism behind such an effect of the analysed compounds and the methanol extract from the leaves of $S$. balsamita is analogical to that of the parthenolide. It is known that the parthenolide interacts with transient receptor potential ankyrin 1 (TRPA1) nucleophilic sites, which leads to the inhibition of nociception and neurogenic vasodilatation in the trigeminovascular system. Moreover, parthenolide and the related sesquiterpene lactones have been shown to inhibit the activation of the pro-inflammatory transcription factor, nuclear factor-kB (NF-kB) by different stimuli, such as phorbol esters, tumour necrosis factor- $\alpha$ and hydrogen peroxide [6]. The analysed compounds may inhibit serotonin release through its effect on protein kinase $C$ (PKC). The activation of PKC by phorbol esters resulted in a reduction of serotonin uptake in endothelial cells and platelets cells. PKC is considered a critical regulator of central sensitization and is recognized to be involved in the pathogenesis of chronic migraine. [16] 


\section{Materials and Methods}

\subsection{Plant Material}

Leaves of S. balsamita (Lam.) K.Koch (Compositae) were collected from the Botanical Garden at the Department of Medicinal and Cosmetic Natural Products, University of Medical Sciences in (Poznan, Poland), where the voucher specimens (voucher number: 42/2014) are deposited. Seeds of S. balsamita were provided by the Botanical Garden in (Teheran, Iran). Flowers, leaves and seeds of S. balsamita were identified by Prof. Karol Latowski from Adam Mickiewicz University in Poznan.

\subsection{Extraction, Isolation and Identification of Compounds from S. balsamita Leaves}

From the leaves of this species, seven germacranolides (parthenolide derivatives) were isolated and identified: balsamin (1), izospiciformin (2), stizolin (3), $9 \alpha$-hydroxyparthenolide (4), $8 \alpha-E$-(4'-hydroxy)-senecioyloxy-9 $\alpha$-hydroxyparthenolide (5), 11ßH,13-dihydrostizolicin (6) and stizolicin (7).

The dried leaves of S. balsamita $(630 \mathrm{~g})$ were crushed and soaked in $\mathrm{MeOH}$. The MeOH extract was evaporated, and the residue was dissolved in $\mathrm{H}_{2} \mathrm{O}$. The aqua solvent was re-extracted with $\mathrm{CH}_{2} \mathrm{Cl}_{2}$. The $\mathrm{CH}_{2} \mathrm{Cl}_{2}$ extract, which was dried with $\mathrm{Na}_{2} \mathrm{SO}_{4}$, was filtrated and evaporated, giving a residue (15.5 g).

The $\mathrm{CH}_{2} \mathrm{Cl}_{2}$ extract was chromatographed on a silica gel with a mixture of $\mathrm{CH}_{2} \mathrm{Cl}_{2}$ and $\left(\mathrm{CH}_{3}\right)_{2} \mathrm{CO}$ (ratio: $15: 1 \mathrm{v} / \mathrm{v}$ ) as an eluent. The polarity was gradually increased with added $\left(\mathrm{CH}_{3}\right)_{2} \mathrm{CO}$. Some collected fractions needed purifying and were rechromatographed on the silica gel with a mixture of n-hexane and $\left(\mathrm{CH}_{3}\right)_{2} \mathrm{CO}$ (ratio: $1: 3 \mathrm{v} / \mathrm{v}$ or 1:8 v/v) or n-hexane and AcOEt (ratio: 1:3 v/v). As a result, the following compounds were isolated: 1 (35.6 mg, melting point [m.p.] 225-228 $\left.{ }^{\circ} \mathrm{C}\right), 2$ (98.9 mg, m.p. $\left.192-195{ }^{\circ} \mathrm{C}\right), 3$ (176 mg, m.p. $\left.183-188^{\circ} \mathrm{C}\right), 4$ (15.3 mg, m.p. $\left.140-142{ }^{\circ} \mathrm{C}\right), 5\left(24.1 \mathrm{mg}, \mathrm{m} . \mathrm{p} .188-190^{\circ} \mathrm{C}\right), 6$ (5.3 mg, amorphous solid) and 7 (342 mg, m.p. $\left.143-144^{\circ} \mathrm{C}\right)$.

The compounds were separated by column chromatography on the silica gel (particle size: 0.063-0.200 mm; Merck [Darmstadt, Germany] Art. 7733). Selected fractions were further rechromatographed on the silica gel with particle sizes of $<0.063 \mathrm{~mm}$ (Merck Art. 7729). The NMR spectra were run on a Bruker Avance 600 instrument using 600 and $150 \mathrm{MHz}$ frequencies for hydrogen nuclei $\left({ }^{1} \mathrm{H}\right)$ and carbon nuclei $\left({ }^{13} \mathrm{C}\right)$, respectively, and tetramethylsilane (TMS) was used as an internal standard (Tables S1 and S2). The spectra were obtained for $\mathrm{CDCl}_{3}$ or DMSO- $d_{6}$ solutions at $298 \mathrm{~K}$. It should be emphasized that NMR measurements were made in aprotic solvents without the addition of solvents causing deuterium exchange, like $\mathrm{CD}_{3} \mathrm{OD}, \mathrm{D}_{2} \mathrm{O}$ or TFA- ${ }_{\mathrm{d}}\left(\mathrm{CF}_{3} \mathrm{COOD}\right)$, but containing residual water, which is crucial for the hydroxyl group detection in the NOESY spectra. Therefore, those solvents must not be dried to remove the mentioned water completely. Chemical shifts $\delta$ are given in ppm, and coupling constants $J$ are given in $\mathrm{Hz}[14,15]$.

Parthenolide did not occur in the analysed plant. This compound was bought from the Sigma-Aldrich company (Saint Louis, MO, USA) and was used for the comparative analysis.

\subsection{HPLC Chromatography Analysis}

The concentrations of dominant compounds in the methanol extract of S. balsamita leaves were determined by HPLC. The analysis was conducted using an Agilent 1200 SL liquid chromatography device with a diode detector and an HPLC precolumn LiChrospher 60 RP-Select B (5 $\mu$ m, 125-4) (Merck). Data and chromatograms were gathered using ChemStation software for the LC 3D system revision B.04.01 SP1 (Agilent Technologies) (Santa Clara, CA, USA). Further analysis was conducted with ChemStation for the LC 3D system revision B.04.01 SP1, Microsoft Excel 2000 (Redmond, WA, USA) and Sigmaplot 11-11.0.0.77.) (Chicago, IL, USA). The mobile phase was composed of water and methanol, and the following gradient elution method was used: $5 \%$ methanol for $0 \mathrm{~min} ; 30 \%$ methanol for $12 \mathrm{~min}$; 30\% methanol for $25 \mathrm{~min}$; and 50\% methanol for $30 \mathrm{~min}$. During this process, the phase flow 
rate was constant and reached $1 \mathrm{~cm}^{3} / \mathrm{min}$. The volume of the dispensed sample was $15 \mu \mathrm{L}$. Absorbance was measured at $\lambda=242 \mathrm{~nm}$.

\subsection{Biological Material}

Ten female Wistar albino rats (approximately $200 \mathrm{~g}$ body weight) were obtained from the Laboratory Animals Breeding Center, Department of Toxicology, Poznan University of Medical Sciences, Poznan, Poland. The Local Ethics Committee for Animal Research (Poznan, Poland) approved the collection of the biological material (resolution no. 20/2012 from 11 May 2012). The research was conducted in the years 2016 and 2017.

Blood samples were withdrawn from the heart chambers $(8 \mathrm{~mL}$ from each animal) and collected into trisodium tubes at a ratio of $1: 9(v / v)$. After centrifugation at $160 \times g$ for 10 min followed by $500 \times g$ for $10 \mathrm{~min}$ at $37^{\circ} \mathrm{C}$, the platelet-rich plasma (PRP) was obtained with a mean number of platelets of $1119+\left[10^{3} / \mu \mathrm{L}\right]$.

Methanol solutions of the dominant compounds 2, 3 and 7 were added to the PRP along with the methanol extract from the $S$. balsamita leaves. The methanol parthenolide solution was used as a reference, and a solution of $0.9 \% \mathrm{NaCl}$ and ammonium dihydrogen orthophosphate (ADP) was used as an aggregation inducer.

\subsection{Enzyme-Linked Immunosorbent Assay (ELISA)}

Ultrasensitive enzyme immunoassay (Serotonin Research ELISA BA E-5937 by Labor Diagnostika Nord GmbH \& Co. KG. (Nordhorn, Germany) was used for the quantitative determination of serotonin. The results were obtained by comparing the absorbance measured from the standard curve prepared using standard samples according to the manufacturer's specification. The analysed compounds and the dry extract were dissolved in 95\% ethanol to obtain solutions with a $20 \mathrm{mg} / \mathrm{mL}$ concentration. Further, $30 \mu \mathrm{L}$ of each solution was washed in $970 \mu \mathrm{L}$ phosphate-buffered saline (PBS). Each sample had a concentration of $0.6 \mathrm{ng} / \mathrm{mL}$. ADP was dissolved in $0.9 \% \mathrm{NaCl}$, and a solution with a concentration of $1 \mathrm{mM} / \mathrm{L}$ was obtained. Four hundred and sixty microlitres of PRP was mixed with $100 \mu \mathrm{L}$ of the extract or other compound solutions for two minutes at $37^{\circ} \mathrm{C}$ at $1000 \mathrm{rpm}$. Two control samples were prepared: K1 and K2, each containing $460 \mu \mathrm{L} \mathrm{PRP}$ with $100 \mu \mathrm{L} 3 \%$ EtOH dissolved in PBS.

\subsection{Statistical Analysis}

The analysed data were not normally distributed (the Shapiro-Wilk test). A comparison of the examined compounds was conducted with the Mann-Whitney U test. The results are displayed as average \pm standard deviation. All statistical analyses were performed using Statistica 12 PL (StatSoft) (Round Rock, TX, USA). All the tests were considered significant at $p<0.05$.

\section{Conclusions}

All the analysed substances (compounds 2, 3 and 7 and the methanol extract from S. balsamita leaves) were found to inhibit the release of serotonin from platelets, and the results were statistically significant. Compound 2 had the most substantial effect, which may be caused by the different structure of its germacranolide skeleton as compared to the other analysed lactones. In compound $\mathbf{2}$, the lactone ring is in position 7-8, not position 6-7 as in compounds 3 and 7 and other parthenolide derivatives.

Compounds 2 and 3 and the methanol extract of the S. balsamita leaves showed statistically significant higher biological activities as compared to parthenolide. The difference in the structure between the parthenolide and its derivatives may be stressed. The results showed that the additional element (substituent on C-8) in the parthenolide structure strengthens the pharmacological effect of the compounds. 
Supplementary Materials: The following are available online-Figure S1: TLC (thin-layer chromatography) of the purified $\mathrm{CH}_{2} \mathrm{Cl}_{2}$ extract and germacranolides isolated from the S. balsamita leaves; Figure S2: HPLC chromatograms of stizolin (S), izospiciformin (I) and stizolicin (Sc); Figure S3: Concentrations of serotonin (unit: $\mathrm{ng} / \mathrm{mL}$ ) in the stizolin sample and the control sample; Figure S4. Concentrations of serotonin (unit: $\mathrm{ng} / \mathrm{mL}$ ) in the izospiciformin sample and the control sample; Figure S5. Concentrations of serotonin (unit: ng/mL) in the stizolicin sample and the control sample; Figure S6. Concentrations of serotonin (unit: $\mathrm{ng} / \mathrm{mL}$ ) in the methanol extract from the leaves of $S$. balsamita sample and the control sample; Table S1: ${ }^{1} \mathrm{H}$ NMR (600 MHz) spectroscopic data of compounds 2, 3 and $7\left(\delta_{\mathrm{H}}\right.$ in ppm, mult; $J$ in Hz); Table S2: ${ }^{13} \mathrm{C}$ NMR $(150 \mathrm{MHz})$ spectroscopic data of compounds 2,3 and 7 .

Author Contributions: G.N., J.N and J.G.-P. conceived and initiated the study. K.K.-P., E.F. and M.N. performed HPLC indications and biological study. J.N. and G.N. isolated and identified the sesquiterpene lactones. M.N. and E.P. prepared the statistical analysis. G.N. and E.F. supervised the experiments. G.N. wrote the manuscript.

Funding: This research received no external funding

Conflicts of Interest: The authors declare no conflicts of interest.

\section{References}

1. Nowak, G. A chemotaxonomic study of sesquiterpene lactones from subtribe Centaureinae of the Compositae. Phytochemistry 1992, 31, 2363-2368. [CrossRef]

2. Picman, A.K. Biological activities of sesquiterpene lactones. Biochem. Syst. Ecol. 1986, 14, 255-281. [CrossRef]

3. Heptinstall, S.; Groenwegen, W.A.; Spangenberg, P.; Loesche, W. Extracts feverfew may inhibit behavior via naturalization of sulphydryl groups. J. Pharm. Pharmacol. 1987, 39, 459-465. [CrossRef] [PubMed]

4. Deen, M.; Christensen, C.E.; Hougaard, A.; Hansen, H.D.; Knudsen, G.M.; Ashina, M. Serotonergic mechanisms in the migraine brain-A systematic review. Cephalalgia 2017, 37, 251-264. [CrossRef] [PubMed]

5. Bogrdorff, P.; Tangelder, G.J. Migraine: Possible Role of Shear-Induced Platelet Aggregation with Serotonin Release. Headache 2012, 52, 1298-1318.

6. Gooshe, M.; Ghasemi, K.; Rohani, M.M.; Tafakhori, A.; Amiri, S.; Aghamollaii, V.; Ahmadi, M.; Dehpour, A.R. Biphasic effect of sumatriptan on PTZ-induced seizures in mice: Modulation by 5-HT1B/D receptors and NOS/NO pathway. Eur. J. Pharmacol. 2018, 824, 140-147. [CrossRef] [PubMed]

7. European Scientific Cooperative on Phytotherapy (ESCOP). ESCOP Monographs: The Scientific Foundation for Herbal Medicinal Products, 2nd ed.; Thieme: New York, NY, USA, 2003; pp. 492-498.

8. Materazzi, S.; Benemei, S.; Fusi, C.; Gualdani, R.; De Siena, G.; Vastani, N.; Anderson, D.A.; Trevisan, G.; Moncelli, M.R.; Wei, X.; et al. Parthenolide inhibits nociception and neurogenic vasodilatation in the trigeminovascular system by targetting TRPA1 chanel. Pain 2013, 154, 2750-2758. [CrossRef] [PubMed]

9. Mittra, S.; Datta, A.; Singh, S.K.; Singh, A. 5-Hydroxytryptamine inhibition property of Feverfew: Role of parthenolide content. Acta Pharmacol. Sin. 2000, 21, 1106-1114. [PubMed]

10. Tassorelli, C.; Greco, R.; Morazzoni, P.; Riva, A.; Sandrini, G.; Nappi, G. Parthenolide is the component of Tanacetum parthenium that inhibits nitroglycerin-induced Fos activation: Studies in an animal model of migraine. Cephalalgia 2005, 25, 612-621. [CrossRef] [PubMed]

11. Freudenstein, J. Experiences with the $\mathrm{CO}_{2}$-extractions of Tanacetum parthenium. In Proceedings of the 46 Annual Congress of the Society for Medicinal Plants Research, Vienna, AT, USA, 31 August-4 September 1998.

12. Urbanska, M.; Nawrot, J.; Dawid-Pac, R.; Kaczerowska-Pietrzak, K.; Morag, M.; Ratajczak, L.; Nowak, G. Detection of pharmacologically active compounds of the Asteraceae family and their chemotaxonomical implications. J. Plant. Sci. 2014, 2, 187-191.

13. Di Giacomo, V.; Ferrante, C.; Ronci, M.; Cataldi, A.; Di Valerino, V.; Rapino, M.; Recinella, L.; Chiavaroli, A.; Leone, S.; Knezewicz, V.S.; et al. Multiple pharmacological and toxicological investigations on Tanacetum parthenium and Salix alba extracts: Focus on potential application as anti-migraine agents. Food Chem. Toxicol. 2019, 133, 110783. [CrossRef] [PubMed]

14. Nawrot, J.; Budzianowski, J.; Nowak, G. Phytochemical profiles of the leaves of Stizolophus balsamita and Psephellus sibiricus and their chemotaxonomic implications. Phytochemistry 2019, 159, 172-178. [CrossRef] [PubMed]

15. Budzianowski, J.; Nawrot, J.; Nowak, G. NMR data for the hydroxyl groups detected by NOESY spectra in sesquiterpene lactones. Data Brief 2019, 25, 104246. [CrossRef] [PubMed] 
16. Wu, B.; Wang, S.; Qin, G.; Xie, J.; Tan, G.; Zhou, J.; Chen, L. Protein kinase $\mathrm{C}_{\mathrm{y}}$ contributes to central sensitization in a rat model of chronic migraine. J. Mol. Neurosci. 2017, 63, 131-141. [CrossRef] [PubMed]

Sample Availability: Samples of the compounds balsamin, izospiciformin, stizolin, $9 \alpha$-hydroxyparthenolide, stizolicin are available from the authors.

(C) 2019 by the authors. Licensee MDPI, Basel, Switzerland. This article is an open access article distributed under the terms and conditions of the Creative Commons Attribution (CC BY) license (http://creativecommons.org/licenses/by/4.0/). 